\title{
A cultura do descarte: o uso e descarte do celular em Campina Grande
}

The culture of discarding: the use and disposal of the cellphone in Campina Grande

\author{
E SANTOS, Diego Ygor Silva; Graduando; Universidade Federal de Campina Grande \\ diego_ygor@hotmail.com \\ DOS SANTOS, José Giovani; Graduando; Universidade Federal de Campina Grande \\ geovani1959@hotmail.com
}

FRANÇA, Marconi Luiz; Professor Doutor Orientador; Universidade Federal de Campina Grande

mfrancauadi@gmail.com

\section{Resumo}

O lixo eletrônico encontra-se atualmente como um dos resíduos que mais são gerados no planeta e que vem crescendo ainda mais por conta do aumento do consumo e da população. A presente pesquisa foi desenvolvida a partir do método quantitativo e semi-sistematizado, com a elaboração e aplicação de questionários, visando entender como o público jovem de 18 a 25 anos interage com este tipo de resíduo, como descartam, se recicla e quais os motivos que os levam a gerar poluição ao meio ambiente, dentro do contexto da Cidade de Campina Grande. E para isto, foi necessário o embasamento teórico, observando questões como Gestão Ambiental, Logística Reversa, Canais de distribuição e Ecodesign. E com a aplicação do questionário, gerou-se dados estatísticos, tratou estes dados e gerou uma solução prática e tecnológica que pode ser facilmente inserida no dia a dia dos jovens.

Palavras Chave: Resíduos Eletrônicos (REEE); Design e sustentabilidade; Crescimento sócioambiental.

\begin{abstract}
Electronic waste is currently one of the most waste generated on the planet and has been growing even more because of the increase in consumption and population. The present research was developed from the quantitative and semi-systematized method, with the elaboration and application of questionnaires, aiming at understanding how the young people aged 18 to 25 interact with this type of waste, how to discard, recycle and what the reasons lead to generate pollution to the environment, within the context of the City of Campina Grande. And for this, it was necessary to base the theoretical, observing issues such as Environmental Management, Reverse Logistics, Distribution Channels and Ecodesign. And with the application of the questionnaire, statistical data were generated, processed these data and generated a practical and technological solution that can easily be inserted in the daily life of the young people.
\end{abstract}

Keywords: Electronic Waste (WEEE); Design and sustainability; Socio-environmental growth. 


\section{INTRODUÇÃO}

Com o avanço tecnológico cada vez mais acelerado no cotidiano da vida, milhões de celulares e equipamentos eletroeletrônicos encontra-se, atualmente, em alto crescimento de produção que rapidamente são transformados em Resíduos de Equipamentos Elétricos e Eletrônicos - REEE. Diante desse fato, os bens eletroeletrônicos ocasionam um descarte de grandes proporções, liberando substâncias e metais pesados, prejudicando assim, o meio ambiente e a saúde humana.

Devido à grande demanda em produtos, a orientação para a sociedade é reaproveitar esses resíduos para que de alguma forma volte como matéria prima para o processo da logística normal de produção, sendo esse o caminho que é descrito por Rodrigues \& Gravinatto (2003):

Nos últimos anos, nota-se uma tendência mundial em reaproveitar cada vez mais os produtos descartados para fabricação de novos artefatos, por meio de processos como a reciclagem, o que representa economia de matéria prima e de energia fornecidas pela natureza.

O Brasil é um país emergente, sendo o segundo maior produtor de REEE das Américas com um volume de 1,5 milhão de toneladas geradas por ano. No país, segundo o $\operatorname{IBGE}(2010)$, foi produzido 194,439 milhões de celulares para uma população de 193,585 milhões de habitantes, é um dos equipamentos eletrônicos mais consumido e, aos poucos, o Brasil vai se adequando à prática de reaproveitar e reciclar alguns componentes desse produto.

Certamente essa nova visão sobre os resíduos envolve não só aspecto ambiental como também envolve as questões sociais, culturais e, sobretudo, econômicas. Formigoni \& Rodrigues (2009) perceberam uma visão diferente dos Brasileiros em relação os Resíduos Sólidos Urbanos (RSUs), vulgarmente conhecidos por lixo urbano, que resulta da atividade doméstica e comercial das cidades. O Brasil, diferente do resto mundo, trata a questão da reciclagem como uma solução socioeconômica, enquanto nos países desenvolvidos a população têm consciência da importância ambiental quando se pratica a reciclagem.

A sociedade industrial está diante de dois entraves a serem vencidos: as novas tecnologias e as ampliações do mercado dos resíduos reciclado em novos produtos. Os resíduos de celulares são mais impactantes do que outros materiais descartados, no Brasil uma política diferente com visibilidade de reutilização com celulares pós-uso, teria um ganho social, econômico e especificamente ambiental.

A Logística Reversa (LR) é uma pratica invertida da logística de produção tradicional, podemos dizer que é um paradigma para os meios de produção atual a ser vencido. É uma maneira de produzir com menos e fazer melhor, segundo Kazazian (2005) é reduzir input e obter mais output. Em outras palavras, o produto é mais raciocínio do uso de material virgem, e dessa maneira, minimizar a velocidade de transformação de bens matérias em resíduos (ecodesign).

Formigoni \& Rodrigues (2009) definem a LR como um processo que está relacionado com reutilização de materiais e produtos. O conceito abrange todas as variáveis do ciclo de vida do produto: manusear, transportar, armazenar um produto do destino final até o seu ponto de origem para reutilização, reciclagem, manutenção, entre outros.

Para Bowersox (2006, p.317-318) a função da Logística Reversa tem o propósito de fazer um fluxo de caixa com a reciclagem e disposição de produtos danificados ou com defeito, 
mantendo o inventário da empresa controlado e regular.

E de maneira direta, Donato (2008) define Logística Reversa como uma parte do gerenciamento que se preocupa com o processamento do retorno dos resíduos para cadeia produtiva.

Nesse cenário, pode-se constatar a relevância que Logística Reversa aliada ao desenvolvimento de serviços e produtos sustentáveis ou produtos leves (ecodesign) que priorize as questões ambientais. Esse trabalho teve o objetivo de pesquisar a cultura as implicações do uso e pós-uso de aparelhos celulares com determinado público residente na cidade de Campina Grande, Paraíba/Brasil.

\section{METODOLOGIA}

A presente pesquisa foi desenvolvida com elaboração e aplicação de questionários para o público-alvo de jovens de 18 a 25 anos de idade, com o objetivo de realizar uma pesquisa do tipo quantitativa, buscando analisar como é realizado o descarte dos smartphones atualmente na cidade de Campina Grande.

\subsection{ETAPAS}

Visando de entender a compra, uso, conserto e pós-uso do celular e outras informações pertinentes ao objetivo do Projeto,a pesquisa foi desenvolvida pelas seguintes etapas:

- Pesquisa bibliográfica através de sites da internet, livros, revistas, artigos acadêmicos entre outras fontes de pesquisa;

- Elaboração e aplicação de questionário do tipo semisistematizado aos consumidores de celulares do tipo Smartphone com idade de 18 a 25 anos;

- Elaboração e aplicação de questionário do tipo semisistematizado aos "Técnicos" de consertos e venda de celulares no Shoppings de camelôs;

- Pesquisa de campo em empresas e estabelecimentos comerciais para observar se há alguma atividade de coleta de celulares;

A seguir algumas questões sistematizadas dos questionários aplicados.

\section{Questionário para consumidores}

- Idade, gênero, renda e nível de instrução;

- Quantos celulares você possui?

- Por quanto tempo utiliza um celular até trocá-lo por um novo?

- Quais os motivos que levam você a trocar os celulares? (Defeito, modelo mais novo, outro)

- Quando troca de celular, qual é a destinação que é dada para o celular antigo? (guarda, joga no lixo comum, devolve em empresas, vende, outros)

- Você já destinou algum celular para reciclagem?

- Tem conhecimento que aparelhos celulares podem ser reciclados?

- Qual o seu conhecimento sobre o lixo eletrônico?

- Você conhece as substâncias encontradas no celular? 
- Ao comprar um celular, as empresas te orientam na forma certa de descartar o seu celular?

Questionário para "Técnicos" de consertos e venda de celulares no Shoppings de camelôs e o Shopping Partage de Campina Grande

Para os técnicos de consertos e vendas de celulares nos Shoppings de camelôs e algumas lojas de celulares no Shopping Partage de Campina Grande, foi aplicado um questionário não sistematizado, foram levantadas informações com perguntas soltas em relação se eles faziam reciclagem, se havia alguma coleta seletiva para os celulares, se orientavam os consumidores para fazer a reciclagem dos celulares a pós o uso e descarte e se recebiam celulares danificados para o reaproveitarem de peças e baterias.

\section{REFERENCIAIS TEÓRICOS}

As considerações estudadas e observadas a seguir foram de fundamental importância para a compreensão e progresso deste projeto, e a inclusão destes assuntos no presente artigo visa fundamentar algumas decisões que foram tomadas para o desenvolvimento da solução.

\subsection{PRINCIPIOS DA GESTÃO AMBIENTAL}

Todo o processo de mudança ou adaptação que interfere no ambiente natural para satisfazer necessidades de uma empresa, individuais ou sociais dos seres humanos, inicia-se um processo de gestão ambiental que deve ser administrado pelo poder público.

A gestão pública na área ambiental, poderá trabalhar procurando reduzir os impactos ao meio ambiente. Paratanto, relembram Philippi Jr, Roméro e Bruna (2004), como é importante que o gestor entendae analise o ambiente natural e suas disponibilidades, bem como o ambiente construído,relacionando-os ao homem e suas atividades.

Segundo Barbieri (2004), a gestão ambiental é entendida como um conjunto de diretrizes,em que a atividade administrativa tem como objetivo reduzir ou eliminar os danos causados ao meio ambiente pela ação humana. Há três dimensões numa proposta de gestão ambiental: a primeira é a dimensão espacial, a qual se refere à área em que se espera que as ações tenham eficácia; a segunda é a dimensão da temática que delimita as questões ambientais às quais as ações se destinam; e por fim, a dimensão institucional, a qual se refere aos agentes que tomaram as iniciativas.

Segundo Donaire (1999) é possível ganhar dinheiro e proteger a natureza ao mesmo tempo, embora seja difícil para as empresas se adaptarem e introduzirem um modelo ecologicamente correto nos processos de desenvolvimento dos produtos a gestão ambiental pode trazer oportunidades. Uma dessas oportunidades pode ser a reciclagem de materiais que tem e pode oferecer grande economia para os setores produtivos das organizações, com o reaproveitamento interno da matéria prima e visibilidade positiva que as empresas podem adquirir com essas mudanças.

Diante do contexto apresentado, observa-se a que as empresas e o poder público devem ter uma visão e uma preocupação maior com os recursos da natureza, e que é possível implementar o sistema de gestão ambiental em sua administração e setor produtivo, procurando equilibrar o ganho financeiro com a redução de impactos no meio ambiente.

\subsection{A LOGÍSTICA REVERSA}


O grande crescimento na oferta de novos celulares, com ciclo de vida cada vez mais limitado, o aumento do poder aquisitivo da população e a grande massa de publicidade em relação aos novos modelos cada vez mais sofisticados e inovadores fizeram com que o consumo e consequentemente o lixo eletrônico de celulares aumentasse significativamente. $O$ cenário de abundância de produtos com ciclos de vida menores faz com que produtos retornem mais rapidamente ao meio ambiente, causando impactos ambientais. (LEITE, 2012).

Durante anos, a logística reversa era voltada unicamente a entrega dos produtos aos clientes e os fabricantes não tinham responsabilidade por seus produtos após a venda, no entanto, com o aumento da população, da velocidade de descarte dos produtos e a com a grande preocupação ecológica da sociedade cada vez mais eminente, novas legislações ambientais, as preocupações com a imagem corporativa e os novos padrões de competitividade de serviços ao cliente tem levado cada vez mais a criação de canais de coleta que reduzam a quantidade de produtos descartados no meio ambiente.

De acordo com Rodrigues (2010), a logística reversa trata de mover o produto do destino final para o retorno ao ciclo de negócios (canal reverso). Caso não seja possível reutilizá-lo de alguma forma, o produto deverá ter uma disposição final adequada.

Leite (2012) define logística reversa de pós-consumo sendo o retorno de produtos para reutilização ou por terem atingido o fim da sua vida útil, bem como os resíduos industriais em geral.

Já a logística reversa de pós-venda está relacionada à satisfação dos clientes, tendo em vista que as empresas estão cientes dos custos e benefícios do processo de logística reversa. O mesmo não ocorre para a logística reversa de pós-consumo, já que o produto foi consumido, e a responsabilidade da cadeia que levou o produto até o cliente não está suficientemente clara.

Portanto, para que a logística reversa realmente aconteça e funcione, tanto para as empresas como também para os consumidores, é necessário que a sociedade tenha informação educação e um estímulo sobre como proceder para dar aos resíduos sólidos uma destinação final ambientalmente adequada e os comerciantes devem fornecer ais consumidores informações e canais reversos para os produtos consumidos.

\subsection{CANAIS DE DISTRIBUIÇÃO REVERSOS (CDRS)}

Os canais de distribuição reversos ou simplesmente CDRs constituem todas as etapas ou meios necessários para o retorno de uma parcela dos produtos comercializados, independente dos motivos, sejam eles relacionados a defeitos de fabricação, prazo de validade vencido, ciclo de vida útil encerrado ou reaproveitamento de embalagens, ao ciclo produtivo da empresa. De acordo com Leite (2003), os CDRS são as formas, etapas e meios de que uma parcela dos produtos comercializados no mercado retorna ao ciclo produtivo de uma determinada empresa após o seu uso e descarte. As empresas podem se beneficiar de maneira bem positiva com a implementação e utilização desses canais de distribuição reversos, pois ao mesmo tempo em que as organizações podem se beneficiar com o retorno da matéria prima ao setor produtivo elas também transmite uma imagem de preocupação e cuidado com as questões ambientais podendo gerar uma estratégia de marketing com esse tema.

\subsection{ECODESIGN}


Os princípios do ecodesign se baseiam como uma ferramenta importante não só para a redução de custos de uma determinada empresa, melhoria da qualidade dos produtos e/ou melhoria dos aspectos ambientais, mas também é importante por contribuir significativamente no estabelecimento de novas estratégias de mercado que são fundamentais para que as empresas se tornem cada vez mais responsáveis e competitivas.

Segundo Johansson (2002), o ecodesign são ações tomadas no processo de desenvolvimento do produto, visando à minimização dos impactos ambientais do produto ao longo de todo o seu ciclo de vida, sem comprometer outros requisitos fundamentais esperados para o produto tais como performance funcional e custo de produção.

No caso, o conceito de ecodesign juntamente com o projetista de produtos, visa justamente minimizar, ou até mesmo, eliminar os impactos ambientais em todas as etapas do ciclo de vida de um determinado produto e, ao mesmo tempo, trazer melhorias para a qualidade do produto e redução de custos, que ainda assim, devem ser levados em consideração no processo de desenvolvimento de produtos.

Com isso, o desenvolvimento de produtos deve ser de maneira sustentável, de modo que um determinado produto possibilite atender as necessidades do presente sem comprometer a habilidade das futuras gerações de encontrar suas próprias necessidades (United Nations, 2008).

Sendo assim, o ecodesign pode ser um serviço que pode gerar estratégias que se preocupe com o meio ambiente e com questões de lucratividade ao mesmo tempo para as empresas, relevando a importância de adotar este tipo de conceito justamente por ser uma oportunidade de realizar bons negócios, utilizando-se de estratégias que pode aumentar a lucratividade, através de práticas relacionadas à proteção ambiental como a remanufatura e reutilização, a maximização do uso dos recursos naturais, o destino ambientalmente correto de peças e componentes no que tange à reciclagem, dentre tantos outros meios de práticos e lucrativos para as empresas.

\section{RESULTADOS E DISCURSÕES}

Na visita realizada ao Shopping dos Camelôs localizado na cidade de Campina Grande no dia 15/02/2018 às 14:30hrs PM, foram entrevistados 5 assistentes técnicos informais. Algumas perguntas sobre como era realizado o descarte; se os resíduos tinham uma destinação conforme a PRS, entre outras. A maioria respondeu que não realizavam a reciclagem e os resíduos não eram colocados separadamente dos resíduos orgânicos. Outra informação obtida por questionamentos não sistematizados foi que a parte interna dos celulares (sistemas, circuitos, placas, baterias, etc) como a externa, eram jogados fora. Mais de $50 \%$ dos entrevistados desse local afirmaram que reaproveitavam peças que ainda funcionavam em outros celulares danificados. Em alguns momentos, houve "técnicos" que não responderam algumas perguntas em relação a leis, reciclagem e obtenção daqueles celulares que eram comercializados nos estabelecimentos. Perguntamos também, qual o público que geralmente mais consome no local e a resposta indicou pessoas jovens de 20 a 30 anos de idade, que demanda celulares de alta capacidade de processamento, com câmera e função de touchscreen. A média de venda é de 3 a 4 celulares seminovo/dia por comerciante

A visita ao Shopping Partage no dia 20/02/2018 às 9:42:00hrs AM da cidade teve o objetivo de encontrar informações, lixeira ou qualquer tipo de informação sobre o descarte dos REEE. Durante a visita observou-se que as lojas especificas em venda de celulares e aquelas que vendia 
outros produtos não possuía sequer uma lixeira para resíduos sólidos, um local para depositar REEE era algo fora do contexto. Entramos em contato com os gerentes dos estabelecimentos comerciais de grande porte como Hiper Bompreço e Insinuante que oferecem diversas marcas de celulares. Ambas não realizam este tipo de orientação para o pós-uso desse produto e a idade média do público consumidor é a mesma identificada no Shopping dos Camelôs, entre 20 e 30 anos de idade.

No Shopping Partage é também comum a procura de celulares mais potentes, no entanto, o consumo destes celulares é maior no shopping, variando em média de 15 a 20 por dia. Isso justifica a questão da nota fiscal, por ser uma garantia ao consumidor de trocar e de ter uma assistência técnica grátis e especializada. Contudo, os preços dos celulares são de custo maior do que no Shopping Camelô, por serem produtos novos e com garantia.

A pesquisa procurou também outra fonte, a administração do Shopping com objetivo de saber a opinião sobre os métodos adotados em relação a problemática REEE e a reciclagem do resíduo ou se havia alguma norma, orientação para a separação, reciclagem e destinação dos resíduos. Diante dos questionamentos, a administração não compartilhou nenhuma informação em relação às questões abordadas.

De acordo com Ribeiro (2010) existem diversos destinos para os rejeitos de centros comerciais, os mais comuns ainda são os aterros sanitários.

Embora os estabelecimentos comerciais não se preocupem com a divisão do lixo da maneira seletiva, a reciclagem básica dos resíduos gerados diariamente seria fundamental para um desenvolvimento mais sustentável socioambiental e das empresas.

\subsection{QUESTIONÁRIO APLICADO AOS CONSUMIDORES}

O questionário aplicado foi realizado na internet com 35 pessoas da cidade de Campina Grande, sendo $47,1 \%$ mulheres e 52,9\% homens. Dentre essas 35 pessoas, as idades variaram bastante. O questionário foi aplicado para pessoas de idade que variam de 18 a 25 anos de idade. Dentre as 35 pessoas, 42,3\% possuem a idade de 21 a 23 anos de idade. As outras pessoas possuem menos de 21 e mais de 23 , o que representa uma porcentagem menor das pessoas. Isso significa que a maior tendência do consumo parte mais de pessoas entre esta faixa de idade, justamente por precisarem deste tipo de produto, uma vez que a maioria deste público é estudante universitário ou já trabalham.

Foi observado através dos resultados que esse público consome mais que um celular. A quantidade utilizada está diretamente relacionada com o poder aquisitivo e questões pessoais. Observe o gráfico (Figura 1): 
Figura 1 - Gráfico da quantidade de celulares por pessoa na faixa etária de 18 a 25 anos

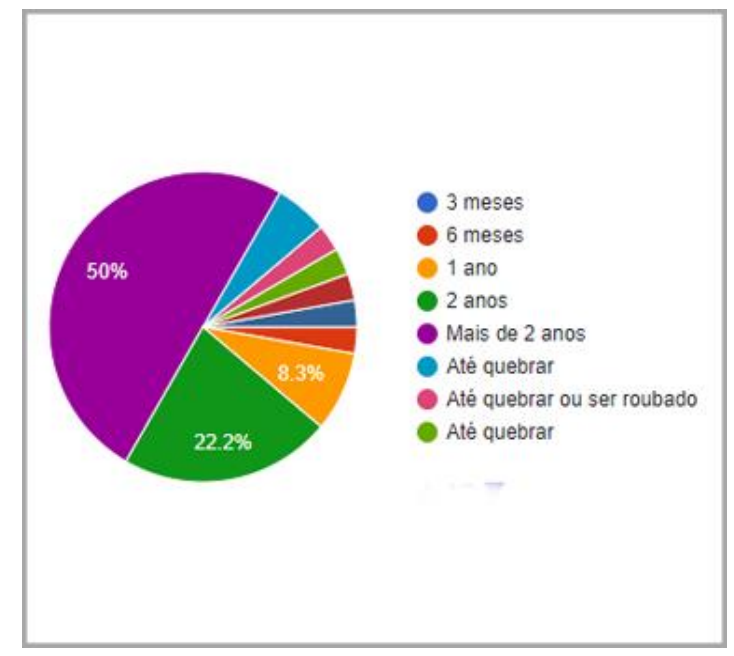

Fonte: Do autor, 2018

O gráfico (Figura 1) mostra que $80,6 \%$ das pessoas possuem apenas 1 celular, outras $16,7 \%$ possuem 2 celulares e, apenas 2,7\% possuem mais de 3 celulares. Ou seja, os estudantes que não possuem uma renda muito alta, não conseguem consumir muito destes tipos de celulares, apenas as pessoas que já trabalham e que utilizam 1 celular para cada função, por exemplo: 1 celular para assuntos da universidade, 1 celular para assuntos do trabalho e outro celular para assuntos familiares.

Em relação aos motivos de troca dos celulares, houve bastantes motivos para explicar a troca do produto, como mostra o gráfico na página a seguir (Figura 2):

Figura 2 - Gráfico sobre os motivos para a troca dos celulares

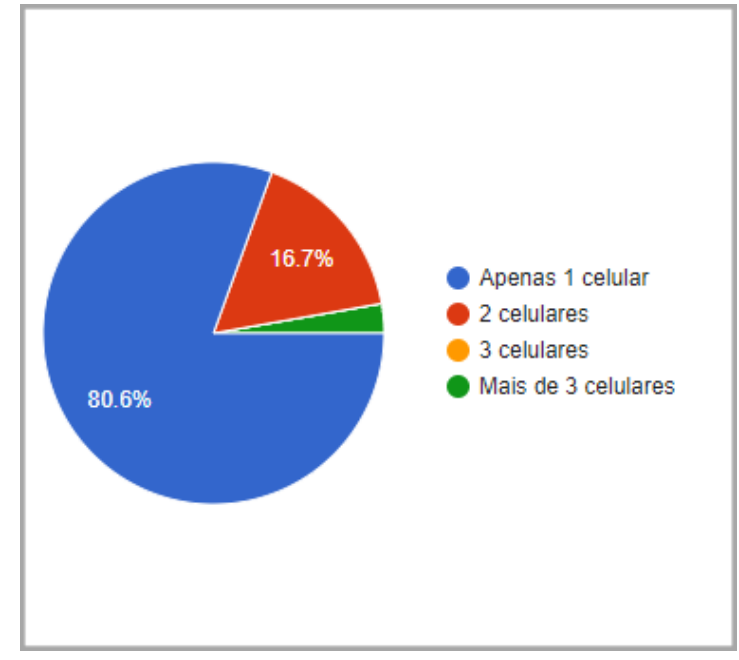

Fonte: Do autor, 2018

Um dos principais motivos o tempo de uso, em que $50 \%$ as pessoas utilizam o mesmo 
celular durante 2 anos, o que explica a relação produto x usuário em que se o produto estiver exercendo bem suas funções, o usuário continuará utilizando o produto independente das suas características visuais ou da sua capacidade de funcionamento. Outro motivo é a quebra de alguma parte do produto com $22 \%$, em que algumas pessoas recorrem à assistência técnica e outros não, justamente por uma questão financeira, para não gastar dinheiro em um produto já com defeito ou defasado (Figura 2).

Ainda em relação à troca dos celulares, o que leva as pessoas a trocarem de celular, segundo ao aspecto funcional (Figura 3), como os principais motivos, são:

Figura 3 - Motivos para a troca do celular segundo o aspecto funcional

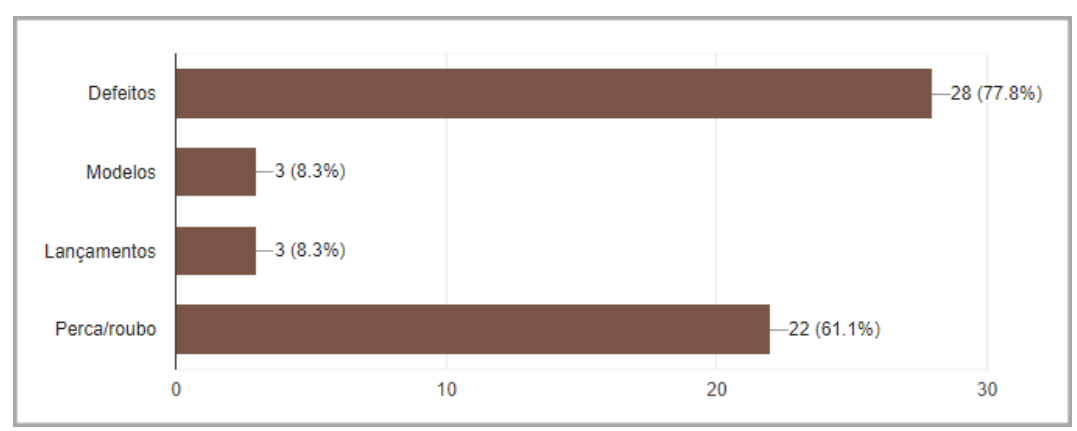

Fonte: Do autor, 2018

Com $77,8 \%$, o principal motivo para a troca dos celulares são defeitos nos sistemas, bateria, carenagens, telas e etc. Como o segundo motivo, $61,1 \%$ é por perca ou roubo destes produtos. Os outros dois motivos são pelo modelo/marcas do celular e pelos lançamentos de novos celulares no mercado (Figura 3).

Quando perguntado sobre o destino que é dado a este tipo de resíduo (Figura 4), o público traz meios de não descartar este tipo de resíduo, como mostra o gráfico abaixo:

Figura 4 - Gráfico que mostra o destino dado aos resíduos eletrônicos pelo público jovem de Campina

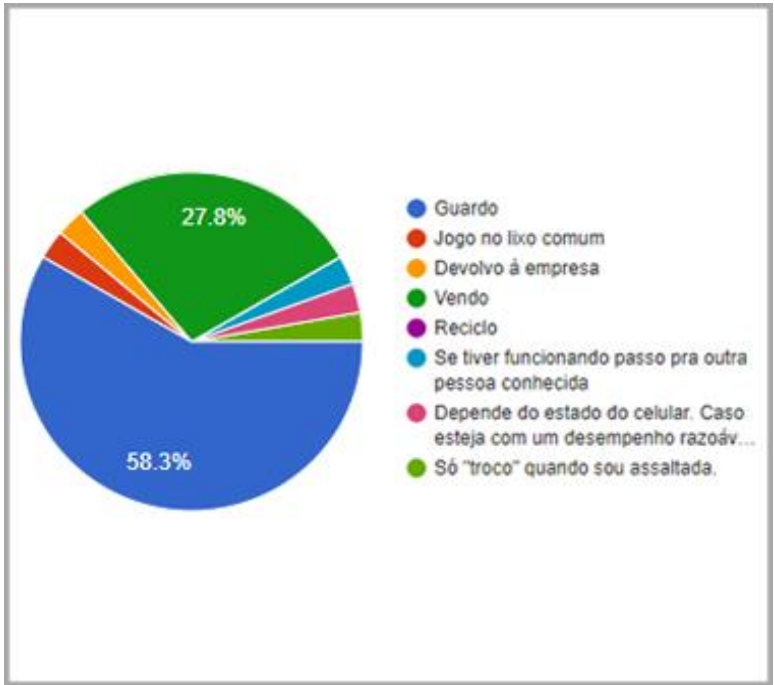

Fonte: Do autor, 2018 
Como mostra no gráfico acima (Figura 4) 58,3\% guardam o celular, $27,8 \%$ vende e apenas $2,8 \%$ devolvem o celular para a empresa. No entanto, nenhum dos usuários levam o resíduo para a reciclagem. Isto mostra que a cultura das pessoas em relação à reciclagem e ao descarte correto deste tipo de resíduo é extremamente baixo, que configura um nível de consciência ambiental a ser trabalhado.

Mesmo sendo possível as pessoas reciclarem este tipo de produto, $94,4 \%$ das pessoas não reciclam este tipo de produto mesmo que $65,7 \%$ das pessoas tem conhecimento de que os celulares podem ser reciclados. Isto é resultado de poucas campanhas de conscientização e até da cultura da sociedade brasileira de não se preocupar em administrar seu próprio lixo que é gerado diariamente.

E ainda, mesmo $82,9 \%$ das pessoas saberem dos riscos ambientais e à saúde das pessoas associado ao descarte inadequado, apenas $5,6 \%$ das pessoas que responderam ao questionário reciclam este tipo de produto através da doação destes resíduos para coletores e postos de reciclagem, o que é preocupante e alarmante, pois gera impactos ambientais, degradação do ambiente por conta dos aterros sanitários, da geração de gás metano e, consequentemente, o gás carbono equivalente e deve-se evitar isso para a prevenção da saúde das pessoas de Campina Grande. No entanto, o que pode justificar esta pouquíssima reciclagem destes resíduos, é o pouco conhecimento sobre as leis e normas e que poucas as pessoas sabem onde há postos para a reciclagem destas pessoas.

O que também problematiza estes pontos são as lojas e empresas que não orientam os consumidores em relação ao depósito e reciclagem deste tipo de lixo, em que mostra o gráfico abaixo (Figura 5):

Figura 5 - Gráfico que mostra o destino dado aos resíduos eletrônicos pelo público jovem de Campina

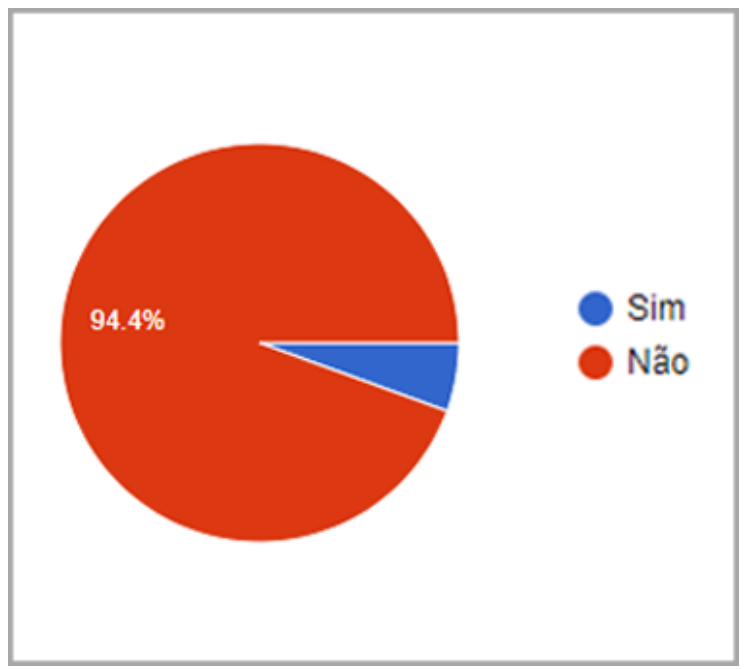

Fonte: Do autor, 2018

Como mostra o gráfico, $94,4 \%$ das pessoas disseram que as empresas não orientam de nenhuma maneira o descarte adequado destes tipos de resíduos. Mas isso pode ser justificado também por conta de que, $83,3 \%$ das pessoas não conhecem sobre a Política Nacional de Resíduos 
Sólidos (lei federal no 12.305), sendo uma forma de proveito pelas empresas de não orientarem as pessoas que consomem este tipo de produto.

Ao perguntar para as pessoas que foram entrevistadas pela internet e conhecem algum local onde é feito a coleta do lixo eletrônico, foi adquirido informações sobre alguns locais, como:

- Supermercados Extra;

- IFPB, João pessoa;

- UFCG, Campina Grande;

- SESC, Centro.

\section{SIMILARES}

Na cidade de São Paulo em 16 de abril de 2008, a claro lançou um projeto em suas lojas que monitora todo o sistema de reciclagem de celulares, baterias, chips entre outros produtos que faz parte da loja e não estão em uso. Esse sistema trabalha no recolhimento até a destinação final dos produtos. O funcionamento acontece da seguinte forma: $O$ consumidor vai a uma das lojas da operadora e deposita os materiais de qualquer fabricante nas urnas coletoras de maneira prática e rápida, não sendo necessário entrar em contato com nenhum funcionário. Todo o processo de recolhimento, coleta, logística e destinação final do lixo eletrônico é realizado pela empresa GM\&C. Todo o material é homologado no IBAMA e nos órgãos ambientais dos estados. O projeto não tem nenhuma geração de receita para a empresa e busca comunicar aos clientes por SMS e divulgação nas lojas e sites da Claro.

A MOTOROLA tem um programa de reciclagem de baterias de celulares em alguns pontos de vendas. Eles recebem baterias usadas ou danificadas que pode ser entregue em qualquer autorizada da loja. Estas baterias são transportadas e armazenadas em conteiners na empresa em Jaguariúna, interior de São Paulo, no qual são acumuladas e transportadas para serem recicladas na Bélgica. Reciclando baterias desde 1999, a Motorola estima que já evitou que mais de 200 toneladas fossem jogadas no meio ambiente. Em agosto de 2007 originou outro programa chamado Ecomoto, que passou a reciclar também celulares e acessórios. Os consumidores precisam ir até os postos de serviço autorizado Motorola e depositar o aparelho, bateria ou acessório nas urnas.

Em relação a aplicativos e plataformas de reciclagem foi observado o aplicativo e-waste no qual é um sistema similar ao que está em desenvolvimento. A função do mapa com geolocalização que indica os pontos de coleta de lixo eletrônico é um dos pontos positivos. Além disso, há a função de dispor de dicas e orientações sobre os tipos de lixo eletrônico e como descartá-los.

Como pôde ser observado, existem projetos semelhantes ao que se propõe a ser desenvolvido voltado a orientação, reciclagem e destinação dos aparelhos de celulares as lojas. Essas soluções são trabalhadas a muitos anos, conforme visto no primeiro exemplo, devido à grande quantidade gerada desse tipo de lixo. Porém, o que as empresas ainda não fazem, para que os consumidores de fato participem mais efetivamente do processo de coleta desse lixo eletrônico, é estimular, interagir e divulgar de maneira mais eficiente com promoções, publicidade e questões que possam realmente levar aos usuários a importância de descartar o e-lixo em locais corretos e que vão beneficiar as empresas. 


\section{DESENVOLVIMENTO DE SOLUÇÕES}

Através dos resultados obtidos, chegou-se a uma proposta preventiva para as questões sociais, econômica e ambiental baseada na $L R$ e o ecodesign que permite interatividade, orientação e educação em relação aos problemas dos resíduos.

A solução seria o desenvolvimento de um aplicativo/site chamado RECICLA-E, que tem como objetivo, incentivar o descarte e a coleta seletiva do lixo eletrônico de maneira que venha reduzir os custos da coleta seletiva e destinação, permitindo descontos em compras de novos celulares, que quanto mais celulares forem dispostos nos postos de coleta seletiva, mais descontos seriam obtidos no aplicativo. Além disso, o sistema forneceria informações de locais de coleta, pessoas, volume, tipo de aparelho, entre outros dados, tornando um serviço de prevenção para desenvolvimento de produtos "leves" e sustentáveis.

\subsection{INTERAÇÃO DO USUÁRIO E PRODUTO (APLICATIVO/SITE)}

O app Recicla-e possui telas onde o usuário seria levado para 4 funções principais: na tela principal, o usuário possui uma interface com uma mapa que indica os locais ou lojas mais próximas para a reciclagem; a segunda tela possui os locais listados possuindo nome, e-mail, número de telefone e endereço de cada local; na terceira tela o usuário é direcionado para as empresas, possuindo as mesmas informações para que seja possível encontrar o local; e a quarta tela é onde há todas as informações, em relação ao quanto de resíduo que o usuário já reciclou, o quanto de desconto o usuário pode ter em compras futuras e etc.

$\mathrm{Na}$ tela de descontos, o usuário consegue filtrar quais as empresas que realizam este tipo de serviço (da reciclagem do antigo celular por descontos em compras), o quanto que ele consegue adquirir em descontos do produto e o que o usuário pode comprar naquela loja com a troca daquele produto por crédito.

Figura 6 - Principais telas de uso do aplicativo Recicla-E
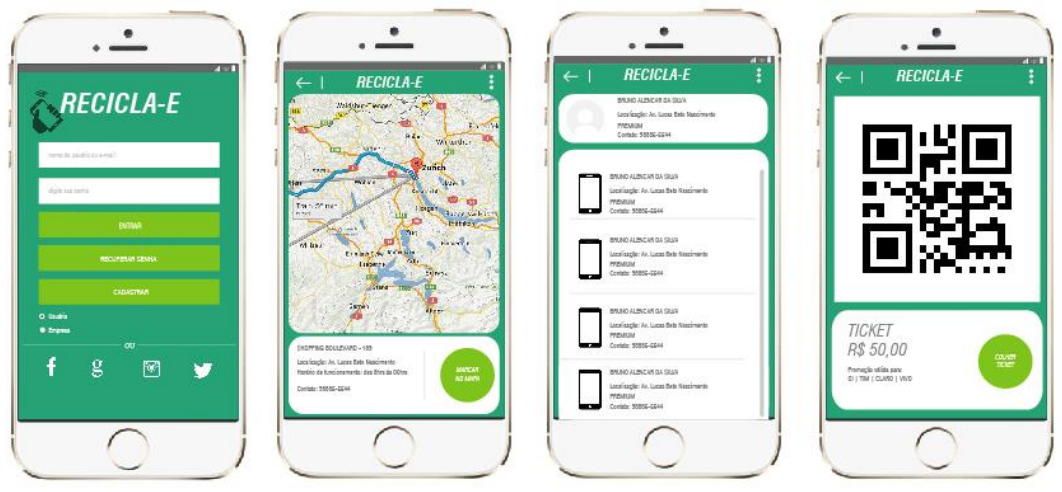

Fonte: Do autor, 2018

Uma forma de bonificar o usuário e chamar mais pessoas para a utilização do app, é que ao convidar uma pessoa que ainda não utiliza o aplicativo e no momento que a pessoa se cadastra, o usuário que fez o convite é bonificado com pontos que podem ser convertidos em descontos.

Além disso, o app tem toda uma parte educacional, em que o usuário é levado para conhecer as leis que regem e envolve toda questão dos resíduos sólidos urbanos e orientações de 
como descartar de maneira correta os celulares nos estabelecimentos, sendo uma forma de conscientizar os usuários que utilizam o produto.

\subsection{COLETOR DE RESÍDUOS DE CELULARES}

Junto ao aplicativo, como proposta de design de produto, foi desenvolvido um coletor seletivo de resíduos eletrônicos que tem como função principal de separar, organizar e direcionar os resíduos que são dispostos pelos usuários para o processo de reciclagem e logística reversa.

Este coletor é separado em 3 módulos principais em que cada módulo recebe um material ou parte diferente, sendo: primeiro módulo para baterias de celulares, o segundo módulo para as carenagens dos celulares e o terceiro módulo para fiações e carregadores. Cada módulo possui uma entrada para colocar o material e uma saída para ser coletado e destinado para a reciclagem do produto.

Figura 7 - Uso do coletor através de QR-code

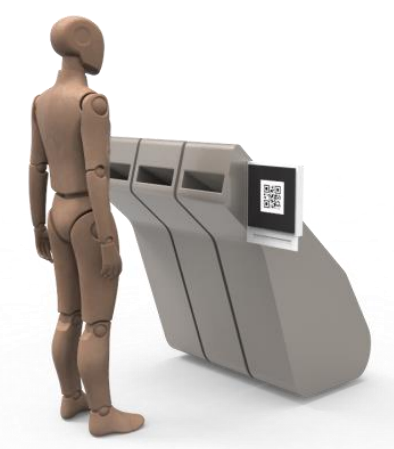

Fonte: Do autor, 2018

Figura 8 - Usabilidade por telefone ou ticket

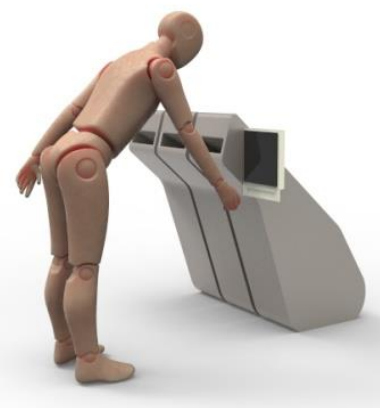

Fonte: Do autor, 2018 


\section{CONCLUSÕES}

Esse trabalho investigou a questão cultural do consumo, conserto e descarte do celular na cidade de Campina Grande/PB, um fato que tem relação com de variáveis de produção, comercialização e ciclo de vida do produto. Após a pesquisa foi possível entender a relação entre comércio, demanda e geração de resíduos. A grande maioria dos vendedores precisam também ser informados sobre problemas dos resíduos nos produtos oferecidos, além dos designers ou desenvolvedores, empresários e indústria, uma vez que eles também têm sua parcela de responsabilidade. Consumidores de celular(es) não tem informação sobre os impactos dos resíduos na natureza, seja em lojas de grande porte ou na birosca de revenda.

Por outro lado, a cultura brasileira é constituída de pouquíssima ou nenhuma informação sobre os problemas dos resíduos, materiais que podem modificar a natureza e causar desequilíbrio social e econômico. Entendemos que, sem consciência do que está acontecendo, o consumidor não desperta para as normas que regulamentam a prática de combate os resíduos e não tem a noção de como administrar o seu próprio lixo.

Sendo assim, mesmo sendo um público que não consomem muito este tipo de produto e não descartam excessivamente, é preocupante por serem jovens que possuem uma mentalidade que não condiz com a realidade social, econômica e ecológica de Campina Grande. Por efeito dominó, estes podem se tornar vetores para as futuras gerações, que certamente a tendência é o aumento da população e, consequentemente em paralelo, o crescimento do consumo. A realidade dos casos nas cidades nos mostra que o descompromisso com a natureza acarreta altos custos para sociedade de consumo e baixa qualidade de vida da população.

\section{REFERÊNCIAS}

ALVES-MAZZOTTI, A. J.; GEWANDSZNAJDER, F. (1999). O Método nas ciências naturais e sociais: pesquisa quantitativa e qualitativa. 2. ed. São Paulo: Pioneira.

ANDRADE, R. O. B.; TACHIZAWA, T.; CARVALHO, A.B. (2000). Gestão ambiental: enfoque estratégico aplicado ao desenvolvimento sustentável. São Paulo: Markron Books.

ARAUJO, Ana Carolina de et al. (2013). Logística reversa no comércio eletrônico: um estudo de caso. Gest. Prod. [online]. 2013, vol.20, n.2, pp. 303-320.

BARBIERI, J. C. (2004). Gestão ambiental empresarial: conceitos, modelos e instrumentos. São Paulo: Saraiva.

BRASIL. Lei no 12.305, de 02 de agosto de 2010. Dispõe sobre a Política Nacional de Resíduos Sólidos. Diário oficial da República. Brasília - DF, 03 de dezembro de 2010.

BOWERSOX, D. J., CLOSS, D. J., \& COOPER, M. B. Gestão Logística de Cadeias de Suprimentos. Porto Alegre: Bookman, 2006.

CONCEIÇÃO, Roberta; PACHECO, Elen. APLICAÇÃO DA LOGÍSTICA REVERSA PARA COLCHÕES DE ESPUMAS DE POLIURETANO: UM ESTUDO DE CASO DE UMA FÁBRICA DE COLCHÕES NO RIO DE JANEIRO, Rio de Janeiro, p. 1 - 9, 2009.

DEMAJOROVIC, Jacques et al. (2012). Logística reversa: como as empresas comunicam o descarte de baterias e celulares? Rev. adm. empres. [online]. vol.52, n.2, pp. 165-178, 2012.

DONAIRE, Denis. (1999). Gestão ambiental na empresa. São Paulo: Atlas. 
DONATO, V. Logística Verde. Rio de Janeiro: Ciência Moderna, 2008.

ROMEIRO, E; Pereira, R. Projeto de produto. Rio de Janeiro: Elsevier, p 215-226, 2010.

FORMIGONI, A; RODRIGUES, Ê. F. A Busca pela Sustentabilidade do PET, através da Sustentabilidade da Cadeia de Suprimentos. São Paulo, p. 1-9, 2009.

HERNANDEZ, Cecilia Toledo; MARINS, Fernando Augusto Silva and CASTRO, Roberto Cespón. (2012). Modelo de Gerenciamento da Logística Reversa. Gest. Prod. [online].vol.19, n.3,pp. 445456, 2012.

JOHANSSON, G. Success factors for integration of ecodesign in product development - a review of state-of-art. Disponível em http://www.sciencedirect.com. Acesso em 21 de agosto de 2002.

KAZAZIAN, T. (org.) Haverá a idade das coisas leves: Design e desenvolvimento sustentável. São Paulo: Ed. Senac São Paulo, 2005.

LEITE, Paulo Roberto. (2012). Logística reversa na atualidade. In: PHILIPPI JR., Arlindo (Coord.).Política nacional,gestão e gerenciamento de resíduos sólidos. São Paulo: Manole.

LEITE, Paulo Roberto. LOGístICA REVERSA: Meio ambiente e competitividade.São Paulo: Prentice Hall, 2003.

MANZINI, E., VEZZOLI, C. Product-service systems and sustainability. Opportunities for sustainable solutions. Paris: UNEP Publisher, 2002.

MANZINI, E.; VEZZOLI, C. O desenvolvimento de produtos. São Paulo, EDUSP, 2002.

Paulo Roberto. (2003). Logística reversa: meio ambiente e competitividade. São Paulo: Pearson Prentice Hall.

PADILHA, Ana Claudia Machado et al.(2009). A equação tecnológica e a gestão de resíduos sólidos: uma análise do descarte de telefones celulares no município de Carazinho - RS. Revista Brasileira de Gestão Ambiental, v. 3, n.1, p. 1-12, jan./dez. Disponível em:<http://www.gvaa.com.br/revista/index.php/RBGA/article/viewFile/369/344>. Acesso em: 20 jun. 2013.

PHILIPPI JÚNIOR, A.; ROMÉRO, M. A.; BRUNA, G. C. (Coord.) Curso de gestão ambiental. Barueri: Manole, 2004.

REIS, Nelson Pereira dos; GARCIA, Ricardo Lopes. (2012). Sistema de gerenciamento dos resíduos industriais e o controle ambiental. In: PHILIPPI JR.,Arlindo (coord.). Política nacional, gestão e gerenciamento de resíduos sólidos. São Paulo: Manole.

RODRIGUES, E. Política nacional de resíduos sólidos: A responsabilidade social e empresarial pelo ciclo de vida dos celulares. Campina Grande. 2010.

RODRIGUES, F. L.; GRAVINATTO, V. M. Lixo - De onde vem? Para onde vai? Ed. Moderna, 2003.

UNITED NATIONS. Undocuments Coopertation circle gathering :a body of global agréments. Report o the World Commission on Environment and development: Our Common Future. Disponível em: http://www.um-documents.net/ocf-02.hym\#1. Acesso em 10 de julho de 2008. 